Chapter 9

\title{
Parenchymal Neuro-Glio-Genesis Versus Germinal Layer-Derived Neurogenesis: Two Faces of Central Nervous System Structural Plasticity
}

\author{
Luca Bonfanti, Giovanna Ponti, Federico Luzzati, \\ Paola Crociara, Roberta Parolisi and \\ Maria Armentano
}

Additional information is available at the end of the chapter

http://dx.doi.org/10.5772/56100

\section{Introduction}

The discovery of neural stem cells (NSCs) at the beginning of the nineties led many people to consider definitively broken the dogma of a static central nervous system (CNS) made up of non-renewable elements [1-3]. In parallel, the occurrence and characterization of adult neurogenesis in the olfactory bulb and hippocampus [3-5] triggered new hopes for brain repair. Twenty years after, the dream of regenerative medicine applied to brain/spinal cord injuries and neurodegenerative diseases is still very far [6,7]. As a matter of fact, adult neurogenesis in mammals occurs mainly within two restricted areas known as 'neurogenic sites' $[3,8]$ : the forebrain subventricular zone (SVZ); reviewed in [9] and the hippocampal dentate gyrus (subgranular zone, SGZ); reviewed in [10]. As a direct consequence of such topographical localization, most of the CNS parenchyma out of the two 'classic' neurogenic sites remains substantially a non-renewable tissue. Actually, most of the traumatic/vascular injuries and neurodegenerative diseases do occur in 'non-neurogenic' regions and no efficacious therapies capable of restoring CNS structure and functions through cell replacement are at present available. Thus, two decades after the discovery of NSCs and the reaching of a satisfactory characterization of adult neurogenic sites, a gap remains between the occurrence of stem/ progenitor cells in the CNS of adult mammals and their effective capability to serve in brain repair. Several aspects do converge in explaining this gap [11], partially accounting for the heterogeneity of CNS structural plasticity in mammals (summarized in Table 1) 
A
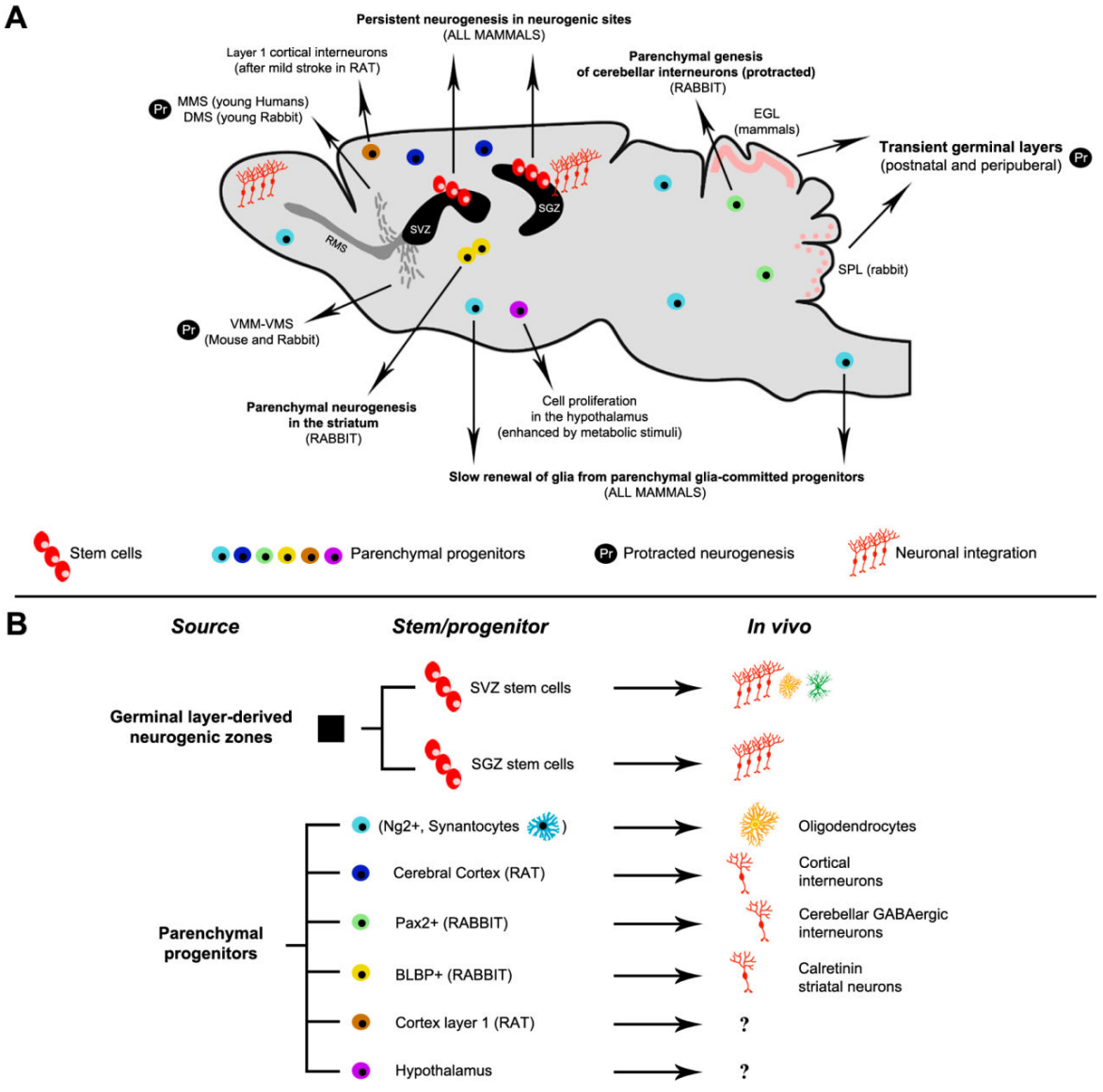

Figure 1. Heterogeneity of postnatal / adult neurogenic processes in different mammals by considering different aspects and mammalian species. B, Schematic summary of the main sources (progenitor cells) of adult mammalian neurogenesis, its outcome in vivo / in culture system, and its possible activation after lesion. In the case of many parenchymal regions, some of these steps are still obscure. BLBP, brain lipid-binding protein; EGL, external germinal layer; GABA, c-aminobutyric acid; Ng2, nerve / glial antigen 2 proteoglycan; NPY, Neuropeptide Y; SGZ, subgranular zone; SPL, subpial layer; SVZ, subventricular zone; VMM, ventral migratory mass; VMS, ventrocaudal migratory stream; MMS, medial migratory stream; DMS, dorsal migratory stream. Adapted from Ref [30].

In this chapter the neurogenic/gliogenic potential of the mammalian brain parenchyma in vivo will be analyzed with particular reference to variables involved in its heterogeneity (e.g., animal species, age, CNS regions; see Figure 1 and Table 1). In particular, these variables do determine the tissue environment in which stem/progenitor cells are immersed, what seems to be extremely important for their activity and outcome. In addition, the origin and nature of stem/progenitor cells would also contribute to their neurogenic/gliogenic potential. It is now well known that cells may have a broader potential than they normally exhibit in vivo when 


\section{Neurogenesis in neurogenic sites}

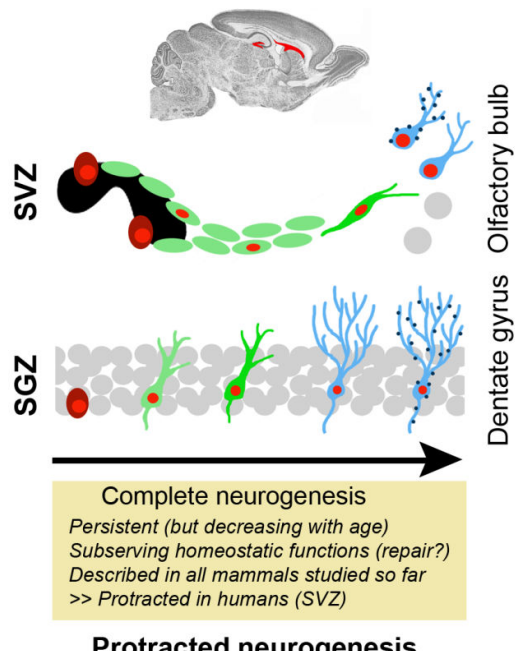

Protracted neurogenesis

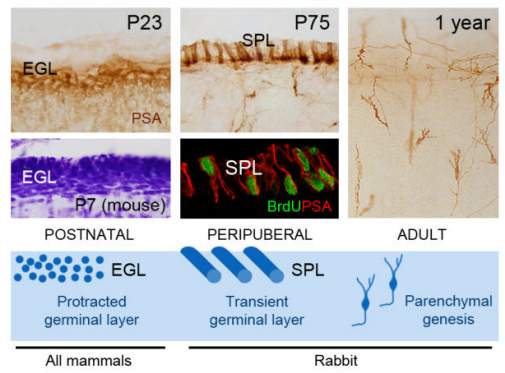

Parenchymal neurogenesis
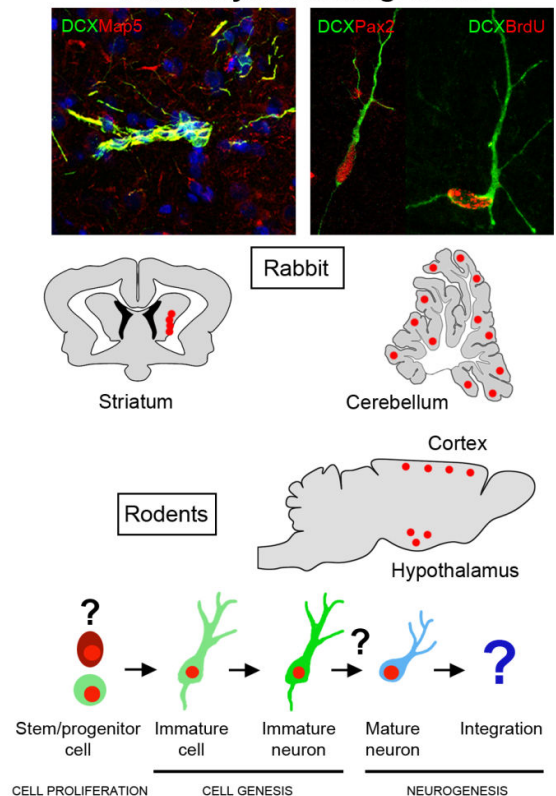

CELL PROLIFERATION CELL GENESIS NEUROGENESIS

Incomplete neurogenesis

Persistent (e.g. rabbit striatum)

Protracted (e.g. interneurons in rabbit cerebellum)

Transient (e.g. EGL in mammals, SPL in rabbits)

Highly variable in mammalian species

PITFALLS: not clear outcome, unknown functions, not clear fate of the progeny, role in repair?

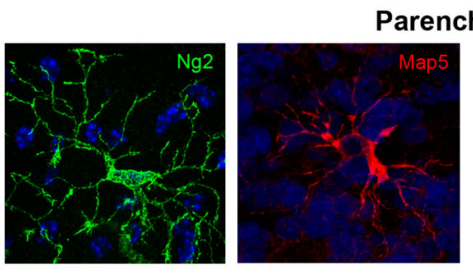

\section{ymal gliogenesis}
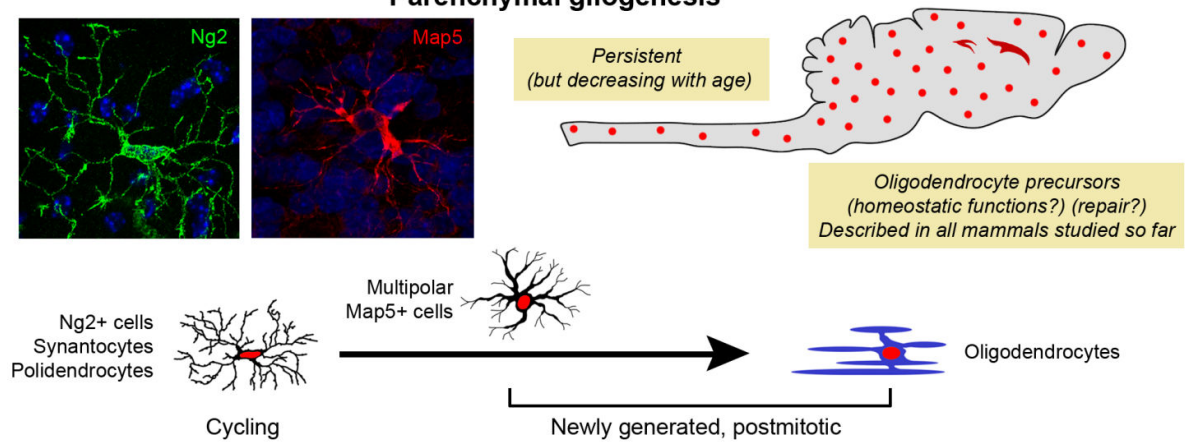

Figure 2. Schematic summary of the features and location of different neurogenic/gliogenic processes occurring spontaneously in the CNS of postnatal and adult mammals. Red dots indicate newlyborn cells. SVZ, subventricular zone; SGZ, subgranular zone; EGL, external germinal layer; SPL, subpial layer (rabbit); PSA, PSA-NCAM; Map5, microtubule-associated protein 1B; P23, postnatal day 23. Question marks indicate lack of knowledge about the origin, late differentiative steps, and final integration of newly generated parenchymal neurons. Adapted from Ref [32]. 
exposed to a different environment, either in vitro or in vivo [29]. Hence, in order to avoid one of the most common misunderstandings, namely the confusion between occurrence of de novo cell proliferation in the CNS tissue and existence of true gliogenic/neurogenic processes, here the attention will be focused on the outcome(s) of the newly generated progeny [30].

\section{A. Variables affecting the nature and features of adult neurogenesis}

Animal species (animal world) General plasticity and persistent neurogenesis are usually reduced across phylogeny; in parallel, the reparative/regenerative potential is also reduced

Animal species (mammals) Unlike previous belief and current bias, remarkable differences in the location and extension of adult neurogenesis do exist among mammals

Age

Some neurogenic processes are extensions of delayed developmental programs (postnatal/protracted neurogenesis) whereas others persist throughout life (persistent neurogenesis). All neurogenic processes are progressively reduced with age

Microenvironment (niche) A well defined neural stem cell niche sustains neurogenesis in neurogenic sites (SVZ, SGZ), whereas a niche has not been characterized in parenchymal neurogenesis

Origin of stem/progenitor cells

Location in the CNS

Function
Neurogenic sites (SVZ, SGZ) directly derive from persistence and modification of preexisting, embryonic germinal layers, whereas for parenchymal cell genesis such direct link is not clear

Location either within a germinal layer-derived niche or in the parenchyma redirects to the two previous points; in parenchymal neurogenesis many variations are linked to local cues of the different CNS regions involved

In physiology: linked to the different ecological niches of the animals (present in all animals)

In repair: linked to the species; in invertebrates and non-mammalian vertebrates the physiological function is associated with function in repair, whereas in birds and mammals it is only linked to physiology/homeostasis of specific systems

B. Main differences between cell genesis in adult neurogenic sites and in the parenchyma

\begin{tabular}{lll}
\hline & Neurogenic sites & Parenchyma \\
Location & Restricted & Widespread \\
Primary progenitor cells & Stem cells & Progenitors \\
Microenvironment & Stem cell niche & Mature neuropil \\
Origin & Germinal layer-derived & No direct link with germinal layers \\
Fate (progeny) & Mainly neurons & Mainly glial cells \\
& (some astrocytes and oligodendrocytes) & (some neurons) \\
Fate (process) & Complete & Incomplete \\
\hline
\end{tabular}

Table 1. Heterogeneity of adult neuro-glio-genesis 
Since developmental changes also account for loss of CNS reparative/regenerative capacities and neuro-glio-genic potential, a paragraph will be devoted to the progenitor cell developmental origin. Then, a brief summary of comparative adult neurogenesis will be given. Evolutionary explanations can provide an understanding of the logic followed (or not) by neurogenic processes through phylogeny, also accounting for the failure in mammalian CNS repair/regeneration and scarce usefulness of adult neurogenesis as a possible solution for brain repair [31,32].

\section{Developmental origin of adult neurogenic/gliogenic processes}

What makes it possible the remarkable neurogenesis occurring in neurogenic sites is their direct origin from embryonic germinal layers which retain stem/progenitor cells along with the 'niche' environment allowing their activity [10,33]. The SVZ and SGZ actually are remnants of their embryonic counterpart, from which they maintain several cellular and molecular aspects [9] in parallel with an adaptation to the changing anatomy of the postnatal and adult brain $[34,35]$.

During development, the CNS originates from the neuroepithelium, pseudostratified epithelial cells that maintain contact with both the ventricular and pial surfaces. As brain thickness increases, neuroepitheial cells transform into radial glia [33,36]. Beside their classic role as scaffolding for migrating neurons during embryogenesis and their subsequent transformation into parenchymal astrocytes of the mature CNS [37,38], radial glia cells behave as stem cells, leading to the genesis of astrocytes, neurons [39,40], and, to a lesser extent, oligodendrocytes [41]. Thus radial glial cells not only serve as progenitors for many neurons and glial cells soon after birth, but also give rise to adult SVZ stem cells that continue to produce neurons throughout adult life [41]. The origin of astrocytes that function as neural progenitors in the adult hippocampus has not been determined experimentally. A connection to radial glial cells, has been suggested even in the hippocampal SGZ [42,43]. The relationship of adult NSCs to their developmental precursors offers clues to the unique characteristics that distinguish these germinal astrocytes from other astroglial cells in the brain parenchyma [33]. Indeed, parenchymal astrocytes lose very early their stem cell potential (around postnatal day 10 in mice [44]), although they can still proliferate in the severe gliosis induced after lesion [45], and resume multipotentiality in vitro [46].

On the other hand, gliogenesis persists throughout the CNS in the form of parenchymal cell genesis capable of creating new oligodendrocytes and, to a lesser extent, astrocytes, throughout life $[12,15]$. Most of this gliogenic activity is attributed to synantocytes/polydendrocytes ( $\mathrm{Ng} 2+$ cells; see below) which are widespread in the CNS tissue and whose origin is still partially obscure. Oligodendrocytes originate from migratory and mitotic embryonic precursors which progressively mature into postmitotic myelin-producing cells. The sequential expression of developmental markers defines distinct phenotypic stages in the oligodendrocyte lineage, characterized by proliferative capacities, migratory abilities and changes in morphology. Most knowledge on this issue comes from studies on the rodent embryonic spinal cord. The first 
oligodendrocyte-committed cell appears at embryonic day 12 (E12) in two columns in the ventral ventricular zone of the motor neuron progenitor domain [47], which is defined by the expression of Olig2 [48]. The embryonic oligodendrocyte precursors are identified by their expression of platelet-derived growth factor alpha receptor (PDGFR $\alpha$ ) [49]. The appearence of the oligodendrocyte lineage-associated markers Olig2 (essential for oligodendrocyte specification and differentiation) and PDGFR $\alpha$ (which permits the expansion of the original precursor population) is dependent on the concentrations of Sonic hedgehog (Shh) [50,51]. One or two days after their appearance, PDGFR $\alpha+$ cells exit the ventricular zone and expand by local proliferation and migration first in the ventral spinal cord region and then dorsally [52]. Finally, they occupy the entire parenchyma by the time of birth [49]. A dorsal source of oligodendrocyte precursors was also shown to contribute to oligodendrogenesis in the spinal cord and hindbrain [53,54]. Fate mapping experiments revealed a double source of oligodendrocyte precursors in the forebrain: cells expressing oligodendrocyte lineage markers, such as Olig1, Olig2, Sox10 and PDGFR $\alpha$, first appear ventrally, in the neuroepithelium of the medial ganglionic eminence, and then migrate laterally and dorsally into all parts of the developing forebrain by E16 to birth [55]. However, several studies have provided evidence for a dorsal and later source of oligodendrocyte precursors in the lateral and/or caudal ganglionic eminence(s), which constitute a second wave of cells invading the cortex only by E18 [54,56]. Nevertheless, adult oligodendrocyte derive only by dorsal precursors, since medial ganglionic eminence-derived precursors were demonstrated to completely disappear after birth [56]. On the whole, it is thought that a unique oligodendrocyte population can derive from progenitor domains defined by different signaling molecules, in contrast to what has been established for neuronal specification during embryonic development, where different parts of the ventricular zone generate distinct types of neurons. In the rodent CNS, once PDGFR $\alpha+$ cells have left the ventricular zone, they start to be termed 'oligodendrocyte progenitor cells' and acquire their most typical marker: an integral membrane chondroitin sulphate proteoglycan named $\mathrm{Ng} 2$ (nerve/glial antigen 2). Ng2 expression becomes detectable only at E14 [57], thus, from E17 to adulthood all PDGFR $\alpha+$ cells are $\mathrm{Ng} 2+$, and, conversely, all the parenchymal (non-vascular) $\mathrm{Ng} 2+$ cells are PDGFR $\alpha+[57,58]$. Early embryonic $\mathrm{Ng} 2+/ \mathrm{PDGF} \alpha \mathrm{R}+\mathrm{OPC}$ are small, undifferentiated, proliferative and motile cells [59]. During embryogenesis, their morphology changes rapidly from a simple oval or polygonal cell body with few unbranched processes to a more differentiated and branched shape with a smaller cell soma $[57,60]$.

Coming back to adult neurogenesis, non mammalian vertebrates including fish, amphibians, and reptiles harbor a more widespread genesis of neurons in the parenchyma. Such processes, due to their location, are apparently independent from the primitive germinal layers. Nevertheless, recent studies which analysed in more detail the origin of adult neurogenesis in fish show that all neurogenic processes likely originate from remnants of the germinal layers; reviewed in [61]. Teleost proliferation zones reflect a general proliferation pattern along the ventricular walls of the brain, distinctly localized in all its subdivisions along the rostrocaudal axis. Between 12 and 16 distinct proliferation zones have been recognized in different teleost species [61]. Hence, across different animal classes, most stem cell populations retain contact to the ventricular system, and they appear as neuroepithelial cells, radial glial or astroglial cell types. The different shapes of these progenitors have been suggested to be a secondary 
consequence of the architecture of the developing parenchyma overlying the ventricular stem cell zone of the embryo [9]. This common pattern across animal species, along with data reported above on the origin of cycling glial progenitors in mammals, indirectly suggests that adult parenchymal neuro-glio-genesis ultimately derives from embryonic germinal layers, yet being able to persist independently in some cases.

\section{Comparative adult neurogenesis and brain repair}

Unlike mammals, other classes of vertebrates including fish, amphibians, and reptiles, harbor a more widespread adult neurogenesis in the parenchyma. In these animals, stem and progenitor cells, in addition to their role in physiological plasticity, also participate in brain repair and regeneration. Failure in mammalian brain repair after traumatic, vascular, and neurodegenerative injuries is due to: i) a strong reduction in the extension of neurogenic regions within the whole CNS; ii) a substantial lack of CNS reparative/regenerative capacity; iii) the fact that adult neurogenic sites subserve specific physiological functions rather than brain repair; for review, see $[11,62,63]$. It is important to note that although the occurrence of good neurogenic potentials would generally favor brain repair (at least by making available stem/progenitor cells) there is not a direct, linear relationship between occurrence of stem/progenitor cells and repair/regeneration, the latter processes strongly depending on the tissue environment and/or tissue reactions; for selected examples of neurogenesis and regeneration see [64].

Neurogenic processes are detectable in wide regions of the CNS in invertebrates and nonmammalian vertebrates $[61,65,66]$, whereas in mammals they are restricted to two privileged areas (neurogenic sites) and the remaining CNS is largely made up of non-renewable tissue $[30,67,68]$. The state of substantial 'general plasticity' and cell renewal existing in the oldest living metazoans, so that all cell types, including neurons, are balanced in their production and loss $[69,70]$, is progressively reduced in vertebrates, although fish and amphibians still maintain remarkable regenerative capacities [71,72]. Then, in birds and mammals a transition between regeneration permissive and non-permissive stages occurs soon after birth, and highly-restricted spots of adult neurogenesis subserve homeostatic functions in specific neural circuits $[73,74]$. The decrease in neurogenic abilities occurs in parallel with topographical/ numerical restriction of germinal layer-derived stem cell niches, whereas the decrease in regenerative abilities occurs in parallel with other aspects: the impossibility to re-access to embryonic developmental programs during adulthood [75], the lack of differentiated cells capable of dedifferentiation [76], the development of a strong immune surveillance [77] and the consequent tissue reactions, most of which detrimental (reviewed in [11,64]). In some cases, the stem cells found in the CNS of non-mammalian vertebrates are deployed for postnatal development of parts of the brain until the final structure is reached. In other cases, postnatal neurogenesis continues into adulthood leading to a net increase of the number of neurons with age. Finally, in other cases, stem cells fuel neuronal turnover. An example is the protracted development of the cerebellar granular layer in mammals, which in adult teleosts actually 
becomes a persistent neurogenesis, where the granular layer continuously grows and no definite adult cerebellar size is reached [61].

In addition, when considering mammals, the failure in CNS repair is a result of evolutionary constraints in which the injured tissue would not favor a strategy of regeneration but rather one of minimizing further damage (e.g., gliotic reaction [78]). Hence, as a consequence of multiple, converging aspects, CNS regenerative capacity in mammals could have reached a point of non-return, in parallel with the persistence of some neurogenic processes which remain mainly focused on physiological functions (e.g., cell renewal/addition in selective neural circuits linked to learning/memory tasks $[73,74])$.

An increased consciousness that the scarce reparative capacity of the mammalian CNS depends on multiple aspects should indicate that it is very unlike the finding of a single molecular factor or pharmacological treatment capable of eliciting repair/regeneration. Comparative results from vertebrate species of different classes have demonstrated that adult neurogenesis is widespread among vertebrates but is employed by different species in different functional contexts $[74,79,80]$, and a growing number of reports show a remarkable heterogeneity even among mammals [17-19]. This variability concerns both the organization/ extension/function of the two neurogenic sites and many examples of parenchymal neurogenesis; reviewed in [30] (see below). This fact, along with our still incomplete knowledge of adult neurogenesis in humans (especially within the parenchyma), partially hampers the reaching of well established 'common rules' which might be used in the translation of experimental preclinical data to human medicine. Thus, dealing with mammalian CNS structural plasticity, high levels of heterogeneity involving different 'types' of neurogenic processes should be taken into account.

\section{Heterogeneity of cell genesis in the mammalian CNS}

We now know that 'classic' neurogenic sites are consistently present in all mammals studied, although with some differences, particularly when the outcome(s) of the neurogenic process are involved [30]. The occurrence of a rostral migratory stream which is active throughout life in rodents but temporally restricted to the postnatal period in humans [81] is a prototypical example of variability among mammals. Indeed, in humans this neurogenic process seems to fall in a delayed developmental process rather than adult neurogenesis (see below).

In addition to neurogenic sites, studies carried out during the last two decades revealed the presence of local, parenchymal progenitors which retain some proliferative capacity in most of the mature mammalian CNS $[12,14,15,17-19,82]$ (Figure 1). This fact suggests that structural plasticity involving de novo cell genesis in the CNS could be more widespread than previously thought. As a consequence of the increasing number of reports investigating adult neurogenesis in mammals, our perception of this biological process has gained new perspectives and nuances; for deeper analysis see $[30,66,83,84]$. What was previously thought as "the genesis of new neurons in restricted brain areas endowed with NSCs", can now be intended as a highly heterogeneous phenomenon (summarized in Figures 1 and 2), whose heterogeneity depends 
on several variables (see Table 1). The main elements of heterogeneity can be summarized as follows: i) the location of progenitors (gathered within restricted neurogenic sites or widely spread out in the parenchyma); ii) the nature of the progenitors (bona fide NSCs versus different types of progenitors); iii) the genetic and molecular features of the progenitors (cell lineage: neuronal-like versus glial-like; identification of differentiative stages dependent on the available markers); iv) the existence or not of well characterized neurogenic niches (absence of niches or occurrence of atypical/non-identified niches in the parenchyma?); v) the extension in time after birth (protracted, transient persistent neurogenesis); vi) the ultimate fate of the progeny in terms of cell lineage (neuronal versus glial; astrocytic versus oligodendrocytic); vii) the ultimate fate of the progeny in terms of cell integration into circuits (complete versus incomplete neurogenesis); viii) the spontaneous occurrence of the process versus its injuryinduced appearance. This latter point could be considered a further step beyond the so-called 'constitutive' neurogenesis, namely the spontaneous, continuous genesis of new neurons as part of a physiologic, homeostatic process [85].

Due to the multifaceted aspects of the above mentioned processes, some problems of terminology can also be raised (see Refs. [30,32]). A common misunderstanding consists of a different use of the word 'neurogenesis', which can be intended either as 'genesis of neurons' or as 'genesis of neural cells', i.e. neurons and glia. Embryonic neurogenesis, namely the process of building up the whole CNS, involves both neuro- and glio-genesis, occurring in largely overlapping and strictly intermingled phases, whereas neurogenesis and gliogenesis can occur separately in the adult. The landscape is even more complex, since research on adult neurogenesis brought developmental neuroscience within the mature brain, and the intermix of structurally plastic changes involving cell genesis/differentiation with the fully assembled adult tissue is accompanied by a previously unexpected intermix of cell lineages (e.g., newly formed neuroblasts arising from astrocytic-like stem cells in vivo). For this reason, in this review article, when not speaking of well characterized cell lineages, the notion of 'cell genesis' instead of 'neurogenesis' will be used, since in most 'neurogenic' processes different cell types can be considered among the progenitors, and different progenies can be generated. Hence, apart from detailed knowledge gathered around the activity of SVZ and SGZ neurogenic sites, many aspects of parenchymal cell genesis remain obscure and/or unesplored, as a consequence of the heterogeneity depicted above. In the last few years, parenchymal neuro-glio-genesis was among the most studied, yet less known, issues, due to the widespread location of the progenitor cells and to the substantial lack of markers which specifically identify their real origin as well as the stage-specific steps of their differentiation. As a consequence, the presence/ absence of neurogenic processes within different CNS parenchymal regions in different mammalian species is still quite controversial and debatable. In most cases, parenchymal cell genesis occurs at low levels, at the limit of technical detection. Furthermore, in some cases it is very difficult to show its final outcome(s), most of the parenchymal neurogenesis appearing 'incomplete' as to the final differentiation/integration of the progeny [30] (Figure 2). Finally, to correctly classify both germinal layer-derived and parenchymal neurogenesis some other aspects should be taken into account, such as the temporal extension of 'protracted'/'transient'developmental neurogenic processes with respect to a 'constitutive'/'persistent' neurogenesis [30]. A further aspect is that of lesion-induced neuro-glio-genesis, namely the genesis 
of new cells as a consequence of different types of CNS injury $[18,25,26,86]$ or altered homeostasis [87]. This is an important point since many lines of research in the field of neural repair directed to manipulate stem cells in the perspective of intracerebral transplantation did not produced substantial therapeutic innovations. As an alternative, another approach might be that of stimulating/modulating the endogenous sources of cell progenitors present both in germinal layer-derived stem cell niches (SVZ and hippocampus) and in the parenchyma.

\section{Parenchymal neurogenesis}

Spontaneous (constitutive) parenchymal neurogenesis can be considered as a very rare phenomenon in mammals, and its regional location has been shown to be dependent on the animal species, age, and physiologicalpathological states [30]. Different examples of neurogenesis occurring outside the two neurogenic sites have been described in rodents $[17,82]$, rabbits $[18,19]$ and monkeys [22,88]. Remarkable differences can be observed between closely related orders (e.g., rodents and lagomorphs $[18,19]$ ), between species (e.g., rat and mouse $[17,23,89,90])$, and even different strains $[91,92]$.

Most parenchymal neurogenesis described in adult rodents seems to occur spontaneously at very low levels, rather being elicited/enhanced after specific physiological or pathological conditions $[17,82,86,87]$ (see below). Dayer and colleagues [17] showed the occurrence of new neurons in the deep layers of the rat cerebral cortex. By labelling newlyborn cells with multiple intra-peritoneal injections of BrdU and using markers of both immature and mature neurons to characterize the new cells through a detailed confocal analysis at different survival times, they demonstrated genesis of new GABAergic interneurons in both neocortex and striatum. At $4-5$ weeks survival time, the $0.4+/-0.13 \%$ of the BrdU+ cells were mature $\mathrm{NeuN}+$ neurons in the neocortex. Morphologic and phenotypic analyses assert these cells belong to different categories of cortical interneurons. Interestingly, although several BrdU+/DCX+/Tuc4+ neuroblasts were identified close to the SVZ periventricular region, the great majority of cortical BrdU+ cells were positive for Ng2. From these data the Authors suggested that adult cortical newborn interneurons might originate from in situ progenitors. Other examples of spontaneous parenchymal neurogenesis have been described in lagomorphs. In rabbits, newly generated neurons are spontaneously produced in other regions of the adult brain starting from local, parenchymal progenitors. In the caudate nucleus, newly formed neuroblasts form longitudinally-arranged, doublecortin (DCX) and PSA-NCAM immunoreactive striatal chains similar to the SVZ chains [18]. These neuroblasts are generated from clusters of proliferating cells which express the astroglial marker brain lipid binding protein (BLBP), and about 1/6 of surviving cells differentiate into calretinin striatal interneurons. Always in rabbits, in sharp contrast with our common knowledge concerning the CNS of other mammals studied so far, a remarkable genesis of cells is detectable in the peripuberal, and to a lesser extent, adult cerebellar cortex [19]. Systemically-administered BrdU detected at different post-injection survival times (up to two months) reveals newly generated PSA-NCAM+/DCX+/Pax2+ interneurons of neuroepithelial origin homogeneously distributed in the cerebellar cortex. Thus, in the striatal and cerebellar parenchyma of lagomorphs new neurons are generated 
independently from the remnants of germinal layers, yet their final outcome and their role in the adult neural circuits remains obscure; reviewed in [30].

The heterogeneity in parenchymal neurogenesis adds to that described for neurogenic processes occurring in adult neurogenic sites, which have been related to adaptation to ecological pressures [80]. At present, this is one of the most satisfactory functional explanations for adult neurogenesis in the entire phylogenetic tree, along with multiple, geneticallydetermined variables spanning from the brain anatomy/developmental history to the animal lifespan [93]. This range of possibilities can also be increased by non-genetic variables, such as experience-dependent cues $[79,80]$.

Among the unsolved issues of parenchymal neurogenesis are the numerous reports which have not been confirmed by further studies or by other laboratories [22,23,26,94-96], along with a series of data which have been denied in studies trying to reproduce the same results [24,97-99]. Without entering in the scientific and technical discussion about these controversies, it is evident that we still not grasp the real limits of parenchymal neurogenesis and that further studies are required before finally accept or deny the existence of some neurogenic processes.

A case placed in between the spontaneous and experimentally-induced neurogenesis, is that of the hypothalamus. Several publications based on experiments carried out on rodents have been reporting data on this brain region as a new site for adult constitutive neurogenesis in mammals (for review see [100]). Under physiological conditions, both in rats [101] and mice $[102,103]$, proliferative activity does occur in the ependymal layer of the third ventricle and within the surrounding parenchyma. In rats, $\mathrm{Xu}$ and collaborators using electron microscopy and immunohistochemistry showed that tanycytes lining the $3^{\text {rd }}$ ventricle proliferate and express molecules usually found in glial, stem-like progenitor cells, such as BLBP and nestin. The presence of putative neural progenitors was further supported by the isolation of cells able to give rise to neurospheres from the hypothalamus. One month after BrdU injection, proliferating cells, some of which expressing Hu protein, were detected in the surrounding parenchyma. Similar results were obtained in mice [102], yet in both rodent species no clear evidence has supported constitutive and complete hypothalamic adult neurogenesis under physiological conditions. A significant increase in hypothalamic proliferating cells can be obtained by performing i.v. delivery of $\mathrm{BrdU}$ ( $350 \%$ more positive nuclei, in comparison to i.p. treated animals), nevertheless, in spite of such cell proliferation the level of neurogenesis in the intact hypothalamus seems to be arrested at a very premature stage. On the other hand, growth factor infusion $[82,101,104]$ or certain experimental conditions/models, such as prolonged heat exposure [105] and the mutant mice investigated by Pierce and Xu (2010), seem to increase neurogenesis in the hypothalamus. Intracerebroventricular infusion of insulin growth factor I in rats [104] triggered an intense proliferation along the $3^{\text {rd }}$ periventricular area and in the parenchyma of the caudal hypothalamus. As concerns the genesis of new neurons, after i.v. treatment with bFGF in rats [101], and CNTF in mice [82], it was shown that proliferation induced by growth factors can be followed by genesis of newborn neurons. Detailed morphological and molecular analyses of the $3^{\text {rd }}$ periventricular region of these animals showed interesting architectural similarities with the SVZ neurogenic niche (e.g., proliferating astroglial cells contacting the ventricle by an apical process bearing a single cilium), with 
tanycytes as primary proliferating elements lining the $3^{\text {rd }}$ ventricle [104]. Yet, additional studies are necessary to clearly demonstrate/confirm whether hypothalamic newborn neurons generated after physiological/pathological stimulation actually become part of the pre-existing circuits playing a role in energy-balance mechanisms.

Taking into account the multifaceted aspects dealing with parenchymal neurogenesis, difficulties encountered in such type of research are not only technical. They are also linked to the occurrence of processes placed in the middle between two well characterized extremes of structural plasticity, such as synaptic plasticity, and 'complete' adult neurogenesis. In a recent review article [30] five levels have been dissected in the neurogenic processes in order to critically evaluate/compare different parenchymal neurogenic events (see also Figure 2). The subsequent steps span from cell division to possible integration of specified/differentiated elements into the CNS tissue, and according to this view, only when any of the five steps are filled the neurogenic process should be classified as 'complete'. As a result, all the parenchymal neurogenic processes described until now can actually be considered as incomplete. This could explain why many claims of neurogenic processes were subsequently refuted because not sustained by experimental evidence. The piriform cortex is one of those regions in which results reported by different researchers are quite controversial; see for example [88,106-108]. Since long time, this cortical region is known to harbor a population of neurons immunoreactive for PSA-NCAM and DCX [108-110], which are two markers highly expressed in newly generated neurons but also present in non newly generated cells [110]. Indeed, deeper investigations have shown that the piriform cortex contains a population of immature, non-newly generated neurons which display very few (or no) synapses and are frequently ensheathed by glial lamellae [108]. These cells, by remaining in an immature state for indeterminate time, can represent a 'reservoir' of neurons that could possibly be recruited into the preexisting neural circuits although not generated ex novo [111].

In conclusion, alternative and multiple forms of plasticity involving neurons can overlap within the so-called non-neurogenic tissue, affecting preexisting cells/circuits and increasing the complexity of the whole picture of brain structural remodeling.

\section{Lesion-induced (reactive) neurogenesis}

Brain lesions have been shown to stimulate neurogenesis in normally non-neurogenic regions such as the neocortex and the striatum. In the neocortex these responses are limited to specific conditions such as targeted apoptosis or mild ischemia $[23,86,112,113]$. By contrast, several lesion paradigms, associated to both strong or mild degeneration and inflammation, have been shown to induce neurogenesis in the striatum $[25,28,114]$. It is unknown if lesioned neocortex and striatum have distinct needs for immature neurons or if the neocortical tissue response is more detrimental for neurogenesis. This fundamental point reveals our very poor knowledge of lesion-induced neurogenesis. Indeed, despite an intense research, we have only little information regarding the nature, fate and potential of the progenitors stimulated by brain lesions, the mechanisms that trigger their activation and eventually their functional role. 
Initial studies in both cortex and striatum reported that a tiny fraction of lesion-induced neurons may differentiate into projection neurons, suggesting that endogenous neuronal progenitors may have the potential to replace degenerated neurons $[23,25,115]$. However, these results have not been confirmed by others $[28,116]$. Moreover, it is now clear that most of the lesion-induced neurons have a transient existence and, at least in the striatum, they do not express markers of projection neurons nor transcription factors involved in their specification $[28,116]$. Several attempts have been made to increase the survival of these cells, with little success [117]. An intriguing possibility to be explored is that lesion-induced neuroblasts occurring in multiple forms of brain injury are committed to transient neuronal types, which contribute to restorative rather than replacement mechanisms [28,63]. This idea is further supported by data showing that a transient existence often characterizes also cortical and striatal neurons generated in normal conditions [18,89].

Neuronal progenitors in the SVZ and SGZ have been shown to respond to injuries by strongly increasing their proliferation, in the SVZ, also migrating towards damaged regions $[25,115]$. In parallel, recent reports have showed that in the degenerated neocortex and striatum, new neurons can also be produced locally from parenchymal neuronal progenitors $[28,83,113]$. In the neocortex, Ohira et al. [86] showed that mild ischemia might stimulate the generation of newborn GABAergic interneurons from progenitors residing in cortical layer I. These cells were not quiescent in normal conditions as they expressed the endogeneous marker of cell proliferation Ki67 and they could be labeled with retroviral vectors. Ohira and coworkers could not define the exact nature of the parenchymal progenitors, which, intriguingly, are very close to the leptomeninges, from which neuronal progenitors have been recently isolated $[118,119]$.

More specific lineage tracing study will be necessary to confirm the real origin of neural progenitors activated after lesion. Lineage tracing has shown that reactive astrocytes isolated from the adult neocortex can give rise to neurospheres in vitro $[46,120]$. To date, the only in vivo evidence that neocortical astrocytes can be neurogenic has been obtained in early postnatal mice after hypoxia/Ischemia [113]. A recent study showed that even if the neural stem cells derived from adult neocortical astrocytes maintain the capacity for self-renew when transplanted in the SVZ, they were still unable to produce neurons [121]. This observation casted some doubts over the actual role of these cells as neuronal progenitors in vivo. Nonetheless, this result may only indicate that the neurogenic potential of cortical and SVZ progenitors rely on distinct factors.

Another example of the in vivo genesis of new neurons within the lesioned brain parenchyma has been obtained in the striatum in a mice model of progressive striatal degeneration, the Creb1 ${ }^{\text {Camkcre }} \mathrm{Crem}^{-/}$mutant mice (CBCM) $[28,122]$. In this model the SVZ acts as a source of postmitotic neuroblasts that enter the striatum from a specific subcallosal migratory stream, as individual elements. Luzzati and coworkers [28] showed that the striatum of CBCM mice contains also tightly clustered neuroblasts which originate locally from parenchymal proliferating progenitors. These cells showed features of intermediate neuronal progenitors of the SVZ and SGZ such as clustering and co-expression of glial (Sox2, Sox9, BLBP) and neuronal markers (Dlx, Sp8, DCX), and the expression of the EGFr [123-126]. This study clearly shows that the mature parenchyma can be permissive to neuronal genesis, although Luzzati and 
coworkers could not trace the origin of the observed striatal parenchymal neuronal progenitors. Nonetheless, two possibilities can be considered: i) striatal neuronal progenitors could derive from the displacement of primary/intermediate progenitors from the SVZ; ii) they could represent local cells becoming neurogenic in response to neurodegeneration.

Together, these data suggests that specific degenerative conditions can stimulate the production of new neurons not only in the neurogenic niches but also in the mature brain parenchyma. This tissue has been classically considered non-permissive for neuronal progenitors, an idea mainly derived from the observation that SVZ and SGZ neural stem cells differentiate only into glial cells when transplanted into the brain parenchyma (for review, see [127]). In light on the accumulating evidence for parenchymal neurogenesis, the classical concept that the mature brain parenchyma is not permissive for the genesis of new neurons should be restricted to SVZ and SGZ progenitors. Yet, future studies should better analyze whether factors modulating the lesion-induced parenchymal neurogenic potential may differ from those acting on 'classic' neurogenic site progenitors.

\section{Parenchymal gliogenesis}

In the past, neurogenesis and gliogenesis had always been kept separate, the latter being considered less important than the former. In recent years, adult gliogenesis has been reevaluated as many populations of progenitor cells with glial-like features and proliferative capacity have been shown to exist in the mature mammalian CNS $[13,15]$. Actually, parenchymal cell genesis in the so-called non-neurogenic regions is mainly gliogenic. In most regions of the CNS, parenchymal progenitors assure a slow process of 'constitutive' gliogenesis leading to renewal of oligodendrocytes and, to a lesser extent, astrocytes $[12,15,128]$. In rodents, the major population of cycling progenitors located outside the germinal niches are $\mathrm{Ng} 2+$ cells morphologically, antigenically, functionally distinct from mature astrocytes, oligodendrocytes and microglia [12-15]. These cells are also called 'polydendrocytes' to highlight their stellate morphology and lineal relationship to oligodendrocytes [15], 'synantocytes' [14] for their contiguity to neurons, or 'oligodendrocyte progenitor cells' (OPCs) because found able of generating myelinating oligodendrocytes $[12,129,130]$. Nevertheless, many polydendrocytes remain as a resident cell population of $\mathrm{Ng}$-expressing cells in the mature white and grey matter after oligodendrocytes are generated. Thus it is widely accepted they represent the fourth CNS major glial population [15], representing 2-9\% of total cells [13]. In the last decade, $\mathrm{Ng} 2+$ cells have generated a lot of interest among neuroscientists, because they show a series of features quite unusual in OPCs. These include: i) an almost uniform distribution in both grey and white matter areas; ii) a stellate morphology; iii) an intimate association with neurons from which they receive synapses $[13,14]$; iv) proliferative capacity in the adult brain $[13,131$, 132], and v) a potential for giving rise to astrocytes and neurons that may be recruited to areas of lesion in the context of brain injury or pathology [128]. At present, it is generally accepted that polydendrocytes are OPCs, even if the demonstration that polydendrocytes differentiate into mature myelinating oligodendrocytes in vivo is challenging, because $\mathrm{Ng} 2$ expression is lost before the terminal differentiation of these cells and the appearance of mature oligoden- 
drocyte antigens. Some observations provide circumstantial evidences for the oligodendroglial fate of polydendrocytes in vivo. For instance, they co-express the PDGFR $\alpha$, and during the first postnatal week, in the corpus callosum and cortex, they start expressing the immature oligodendrocyte antigen $\mathrm{O} 4$ [133]. Polydendrocytes also express the basic helix-loop-helix (bHLH) transcription factors Olig1 and Olig2, which are required for oligodendrocyte specification and differentiation $[132,134]$ as well as Sox9 and Sox10 transcription factors. Moreover, pulse-chase labelling of proliferating cells using 5-bromo-2'-deoxyuridine (BrdU) revealed that the number of $\mathrm{BrdU}+\mathrm{Ng} 2+$ cells decreases while that of BrdU+ oligodendrocytes increases over time $[12,135]$. Cell grafting experiments have shown that polydendrocytes give rise to myelinating cells when they are transplanted into an environment free of endogenous myelinating cells [136]. Recently, more direct evidence for the oligodendroglial fate of polydendrocytes was obtained from cell fate-mapping experiments using transgenic mice that express Cre recombinase (Cre) in Ng2-expressing cells or that express inducible Cre (CreeR), under the regulation of the Cspg4, PDGFR $\alpha$ or Olig2 genes, which enable determination of the fate of polydendrocytes at a given time during development $[95,137,138]$. These studies showed that oligodendrocytes continue to be generated in the mature brain.

Early cell-culture studies showed that OPCs purified from rat optic nerves differentiate not only into oligodendrocytes but also into process-bearing 'type-2 astrocytes' in the presence of serum factors, which led to the concept of bipotential oligodendrocyte type-2-astrocyte (O-2A) progenitor cells [139]. There are now controversial observations suggesting that bipotentiality of polydendrocytes might be real or an in vitro artifact $[136,140,141]$, and most likely these cells are inherently capable of differentiating into astrocytes but are prevented from fulfilling their astroglial fate in the normal in vivo environment [128].

On the whole, while all of these studies consistently support the oligodendrocyte lineage of the $\mathrm{Ng} 2+$ cells, the genesis of astrocytes from $\mathrm{Ng} 2+$ cells is confirmed only during postnatal ages. All these different and sometimes controversial results may be explained by some methodological/technical differences, but may also reflect heterogeneity in progenitor cell populations/subpopulations (mostly not yet identified), which is far to be elucidated [98]. In this context, we have recently identified a population of multipolar glial cells immunoreactive for the microtubule associated protein 5 (Map5) [142], which share features but also differences with Ng2+ progenitor cells [19]. These multipolar, Map5+ cells are newly generated, parenchymal elements of the oligodendroglial lineage, which represent a stage-specific population of polydendrocytes (Crociara et al., in preparation; Figure 2).

\section{Conclusion and future perspectives}

The CNS of mammals, in spite of having lost most of its regenerative/repair capacity with respect to other phyla, is endowed with remarkable plasticity. This property is heterogeneously distributed in different regions and can manifest in different ways. A better knowledge of the various forms of spontaneous and lesion-induced structural plasticity, of their mutual relationships and of the relative underlying mechanisms is fundamental in order to figure out 
new efficacious therapeutic perspectives for brain repair. During the last two decades, the discovery of neural stem cells and the studies on adult neurogenesis have opened the intriguing possibility of cell replacement-aimed therapeutic strategies. Under pressure of this perspective, studies on CNS stem cells and progenitors have increased exponentially, sometimes leading to excessive emphasis about theoretical correlations between neuro-glio-genic processes and brain repair. In this context, focusing on the 'real' neurogenic/gliogenic potential of the mammalian CNS should avoid to turn an exciting biological discovery into a therapeutic illusion. Indeed, the approach of regenerative medicine applied to the CNS is still hampered by overwhelming problems concerning the final integration of both transplanted and endogenously-induced cells [6]. The reason of this failure might be mostly due to evolutionary constraints [78], and to the fact that cell renewal typical of adult constitutive neurogenesis is primarily involved in tissue homeostasis of highly restricted regions, being hardly useful in response to external injury and neurodegenerative brain damage affecting the parenchyma $[11,62]$. On the other hand, the parenchymal cell genesis might represent a new plastic potential to be explored within wide regions of the CNS, including those areas affected by different neurodegenerative diseases and traumatic injuries. With respect to classic SVZ and SGZ neurogenesis, parenchymal neuro-glio-genesis does constitute an alternative source of progenitors, although with different outcomes [30]. Indeed, a vast number of reports currently published in this domain, although accurate and carried out with multiple technical approaches, do suggest that in most cases newly formed elements barely survive and do not fully integrate. In addition, the extreme heterogeneity of parenchymal neuro-glio-genesis makes the brain parenchyma a harsh territory, in which many questions remain unanswered and new ones are opened (see Box 1). For instance, beside a deep knowledge on the cell cycle and early cell lineage in neurogenic sites (see for example $[143,144]$ ), such information is starting to be gathered only in specific perenchymal regions and or situations $[145,146]$. Hence, further studies of parenchymal stem/progenitor cells, on their origin and their different fates and outcomes, should grant new challenges in the multifaceted field of CNS structural plasticity and repair.

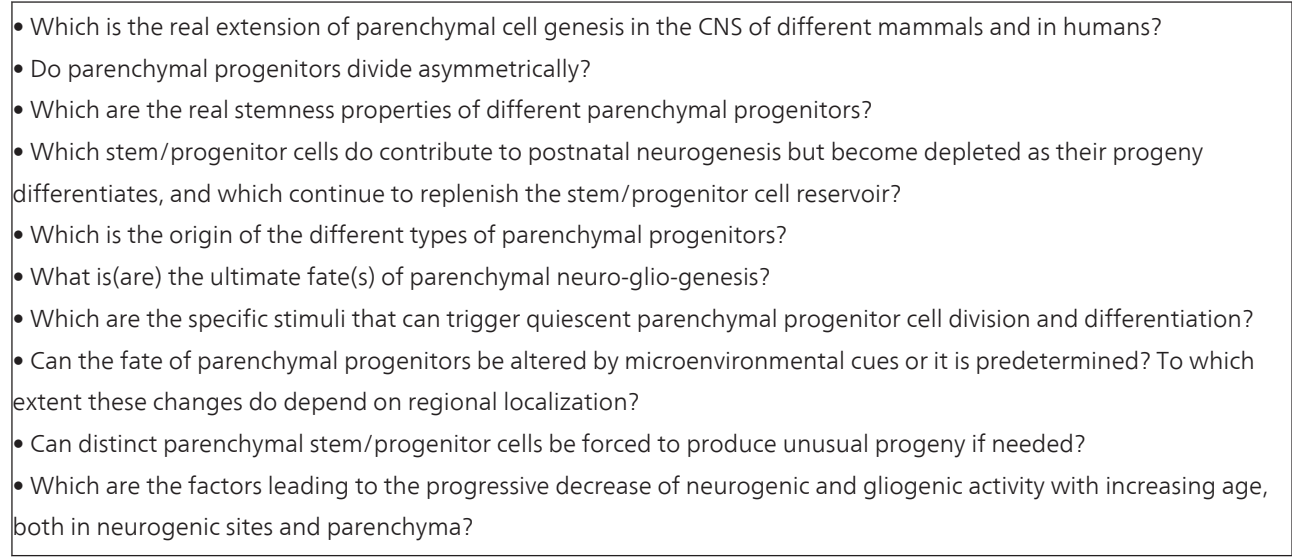

Box 1. Some open questions 


\section{Author details}

Luca Bonfanti*, Giovanna Ponti, Federico Luzzati, Paola Crociara, Roberta Parolisi and Maria Armentano

*Address all correspondence to: luca.bonfanti@unito.it

Neuroscience Institute Cavalieri Ottolenghi (NICO), University of Turin, Italy

\section{References}

[1] B. A. Reynolds, S. Weiss, "Generation of neurons and astrocytes from isolated cells of the adult mammalian central nervous system," Science, vol. 255, pp. 1707-1710, 1992.

[2] C. G. Gross, "Neurogenesis in the adult brain: death of a dogma," Nature Review Neurosciences, vol. 1, pp. 67-73, 2000.

[3] F. H. Gage, “Mammalian neural stem cells,” Science,,vol. 287, pp. 1433-1438, 2000.

[4] C. Lois, A. Alvarez-Buylla, "Long-distance neuronal migration in the adult mammalian brain," Science, vol. 264, pp. 1145-1148, 1994.

[5] F. H. Gage, G. Kempermann, T. D. Palmer, D. A. Peterson, J. Ray, "Multipotent progenitor cells in the adult dentate gyrus," Journal of Neurobiology, vol. 36, pp. 249-266, 1998.

[6] E. Arenas, "Towards stem cell replacement therapies for Parkinson's disease", Biochemical and Biophysical Research Communications, vol. 396, pp. 152-156, 2010.

[7] O. Lindvall, Z. Kokaia, "Stem cells in human neurodegenerative disorders--time for clinical translation?" Journal of Clinical Investigation, vol. 120, pp. 29-40, 2010.

[8] L. Bonfanti, G. Ponti, "Adult mammalian neurogenesis and the New Zealand white rabbit," Veterinary Journal, vol. 175, pp. 310-331, 2008.

[9] Kriegstein, A. Alvarez-Buylla, "The glial nature of embryonic and adult neural stem cells," Annual Review of Neuroscience, vol. 32, pp. 149-184, 2009.

[10] Zhao, E. M., Teng, R. G. Jr Summers, G. L. Ming, F. H. Gage, “Distinct morphological stages of dentate granule neuron maturation in the adult mouse hippocampus," Journal of Neuroscience, vol. 26, pp. 3-11, 2006.

[11] L. Bonfanti, "From hydra regeneration to human brain structural plasticity: a long trip through narrowing roads," The Scientific Word Journal, vol. 11, pp. 1270-1299, 2011. 
[12] P. J., Horner, A. E., Power, G. Kempermann, H. G. Kuhn, T. D. Palmer, J. Winkler, L. J. Thal, F. H. Gage, "Proliferation and differentiation of progenitor cells throughout the intact adult rat spinal cord," Journal of Neuroscience, vol. 20, pp. 2218-2228, 2000.

[13] M. R. Dawson, A. Polito, J. M. Levine, R. Reynolds, “NG2-expressing glial progenitor cells: an abundant and widespread population of cycling cells in the adult rat CNS," Molecular and Cellular Neuroscience, vol. 24, pp. 476-488, 2003.

[14] M. Butt, N. Hamilton, P. Hubbard, M. Pugh, M. Ibrahim, "Synantocytes: the fifth element," Journal of Anatomy, vol. 207, pp. 695-706, 2005.

[15] Nishiyama, M. Komitova, R. Suzuki, X. Zhu, "Polydendrocytes (NG2 cells): multifunctional cells with lineage plasticity," Nature Reviews Neuroscience, vol. 10, pp. 9-22, 2009.

[16] J. Trotter, K. Karram, A. Nishiyama, "NG2 cells: Properties, progeny and origin," Brain Research Review, vol. 63, pp. 72-82, 2010.

[17] Dayer, K. Cleaver, T. Abouantoun, H. Cameron, "New GABAergic interneurons in the adult neocortex and striatum are generated from different precursors," Journal of Cell Biology, vol. 168, pp. 415-427, 2005.

[18] F. Luzzati, S. De Marchis, A. Fasolo, P. Peretto, "Neurogenesis in the caudate nucleus of the adult rabbit," Journal of Neuroscience, vol. 26, pp. 609-621, 2006.

[19] G. Ponti, P. Peretto, L. Bonfanti, “Genesis of neuronal and glial progenitors in the cerebellar cortex of peripuberal and adult rabbits," PLoS One, vol. 3, e2366, 2008.

[20] T.D. Palmer, E. A. Markakis, A. R. Willhoite, F. Safar, F. H. Gage, “Fibroblast growth factor-2 activates a latent neurogenic program in neural stem cells from diverse regions of the adult CNS," Journal of Neuroscience, vol. 19, pp. 8487-8497, 1999.

[21] S. Belachew, R. Chittajallu, A. A. Aguirre, X. Yuan, M. Kirby, S. Anderson, V. Gallo, "Postnatal NG2 proteoglycan-expressing progenitor cells are intrinsically multipotent and generate functional neurons," Journal of Cell Biology, vol. 161, pp. 169-186, 2003.

[22] E. Gould, A. J. Reeves, M. S. Graziano, C. G. Gross, “Neurogenesis in the neocortex of adult primates" Science, vol. 286, pp. 548-552, 1999.

[23] S. S. Magavi, B. R. Leavitt, J. D. Macklis, "Induction of neurogenesis in the neocortex of adult mice. Nature, vol. 405, pp. 951-955, 2000.

[24] D. R. Kornack, P. Rakic, “Cell proliferation without neurogenesis in adult primate neocortex," Science, vol. 294, pp. 2127-2130, 2001.

[25] Arvidsson, T. Collin, D. Kirik, Z. Kokaia, O. Lindvall, “Neuronal replacement from endogenous precursors in the adult brain after stroke," Nature Medicine, vol. 8, pp. 963-970, 2002. 
[26] H. Nakatomi, T. Kuriu, S. Okabe, S. Yamamoto, O. Hatano, N. Kawahara, A. Tamura, T. Kirino, M. Nakafuku, "Regeneration of hippocampal pyramidal neurons after ischemic brain injury by recruitment of endogenous neural progenitors," Cell, vol. 110, pp. 429-441, 2002.

[27] P. Thored, A. Arvidsson, E. Cacci, H. Ahlenius, T. Kallur, V. Darsalia, C.T. Ekdahl, Z. Kokaia, O. Lindvall, "Persistent production of neurons from adult brain stem cells during recovery after stroke," Stem Cells, vol. 24, pp. 739-747, 2006.

[28] F. Luzzati, S. De Marchis, R. Parlato, S. Gribaudo, G. Schütz, A. Fasolo, P. Peretto, "New striatal neurons in a mouse model of progressive striatal degeneration are generated in both the subventricular zone and the striatal parenchyma," PLoS One, vol. 6, e25088, 2011.

[29] J. Ninkovic, M. Gotz, Fate specification in the adult brain: lessons from eliciting neurogenesis from glial cells, Bioessays, 2013, in press.

[30] L. Bonfanti, P. Peretto, "Adult neurogenesis in mammals - A theme with many variations," European Journal of Neuroscience, vol. 34, pp. 930-950, 2011.

[31] L. Bonfanti, F. Rossi, G. K. Zupanc, "Towards a comparative understanding of adult neurogenesis," European Journal of Neuroscience, vol. 34, pp. 845-846, 2011.

[32] L. Bonfanti, The (real) neurogenic/gliogenic potential of the postnatal and adult brain parenchyma, ISRN Neuroscience, vol 2013, pp. 1-14, 2013.

[33] R. A. Ihrie, A. Alvarez-Buylla, "Lake-front property: A unique germinal niche by the lateral ventricles of the adult brain," Neuron, vol. 70, pp. 674-686, 2011.

[34] P. Peretto, C. Giachino, P. Aimar, A. Fasolo, L. Bonfanti, “Chain formation and glial tube assembly in the shift from neonatal to adult subventricular zone of the rodent forebrain," Journal of Comparative Neurology, vol. 487, pp. 407-427, 2005.

[35] L. Bonfanti, P. Peretto, "Radial glial origin of the adult neural stem cells in the subventricular zone," Progress in Neurobiology, vol. 83, pp. 24-36, 2007.

[36] W. Haubensak, A. Attardo, W. Denk, W. B. Huttner, "Neurons arise in the basal neuroepithelium of the early mammalian telencephalon: a major site of neurogenesis," Proceedings of the National Academy of Sciences U.S.A, vol. 101, pp. 3196-3201, 2004.

[37] T. Voigt, "Development of glial cells in the cerebral wall of ferrets: direct tracing of their transformation from radial glia into astrocytes," Journal of Comparative Neurology, vol. 289, pp. 74-88, 1989.

[38] J. P. Misson, T. Takahashi, V. S. Caviness, “Ontogeny of radial and other astroglial cells in murine cerebral cortex," Glia, vol. 4, pp. 138-148, 1991. 
[39] P. Malatesta, E. Hartfuss, M. Gotz, "Isolation of radial glial cells by fluorescent-activated cell sorting reveals a neuronal lineage," Development, vol. 127, pp. 5253-5263, 2000.

[40] S. C. Noctor, A. C. Flint, T. A. Weissman, R. S. Dammerman, A. R. Kriegstain, “Neurons derived from radial glial cells establish radial units in neocortex," Nature, vol. 409, pp. 714-720, 2001.

[41] F. T. Merkle, A. D. Tramontin, J. M. Garcì-Verdugo, A. Alvarez-Buylla, "Radial glia give rise to adult neural stem cells in the subventricular zone" Proceedings of the National Academy of Sciences U.S.A, vol. 101, pp. 17528-17532, 2004.

[42] M. F. Eckenhoff, P. Rakic, "Radial organization of the hippocampal dentate gyrus: a Golgi, ultrastructural, and immunocytochemical analysis in the developing rhesus monkey" Journal of Comparative Neurology, vol. 223, pp. 1-21, 1984.

[43] Seri, J. M. Garcìa-Verdugo, L. Collaudo-Morente, B. S. McEwen, A. Alvarez-Buylla, "Cell types, lineage, and architecture of the germinal zone in the adult dentate gyrus," Journal of Comparative Neurology, vol. 478, pp. 359-378, 2004.

[44] E. D. Laywell, P. Rakic, V. G. Kukekov, E. C. Holland, D. A. Steindler, "Identification of a multipotent astrocytic stem cell in the immature and adult mouse brain," Proceedings of the National Academy of Science U.S.A., vol. 97, pp. 13883-13888, 2000.

[45] M. V. Sofroniew, "Molecular dissection of reactive astrogliosis and glial scar formation," Trends in Neuroscience, vol. 32, pp. 638-647, 2009.

[46] Buffo, I. Rite, P. Tripathi, A. Lepier, D. Colak, A. P. Horn, T. Mori, M. Gotz, "Origin and progeny of reactive gliosis: A source of multipotent cells in the injured brain," Proceedings of the National Academy of Science U.S.A., vol. 105, pp. 3581-3586, 2008.

[47] T. M. Jessell, "Neuronal specification in the spinal cord: inductive signals and transcriptional codes," Nature Reviews Genetics, vol. 1, pp. 20-9, 2000.

[48] H. Takebayashi, S. Yoshida, M. Sugimori, H. Kosako, R. Kominami, M. Nakafuku, Y. Nabeshima, "Dynamic expression of basic helix-loop-helix Olig family members: implication of Olig2 in neuron and oligodendrocyte differentiation and identification of a new member, Olig3," Mechanisms of Development, vol. 99, pp. 143-148, 2000.

[49] N. P. Pringle, W. D. Richardson, "A singularity of PDGF alpha-receptor expression in the dorsoventral axis of the neural tube may define the origin of the oligodendrocyte lineage," Development, vol. 117, pp. 525-533, 1993.

[50] Poncet, C. Soula, F. Trousse, P. Kan, E. Hirsinger, O. Pourquie, A. M. Duprat, P. Cochard, "Induction of oligodendrocyte progenitors in the trunk neural tube by ventralizing signals: effects of notochord and floor plate grafts, and of sonic hedgehog", Mechanisms of Development, vol. 60, pp. 13-32, 1996.

[51] N. P. Pringle, W. P. Yu, S. Guthrie, H. Roelink, A. Lumsden, A. C. Peterson, W. D. Richardson, "Determination of neuroepithelial cell fate: induction of the oligoden- 
drocyte lineage by ventral midline cells and sonic hedgehog," Developmental Biology, Vol. 177, pp. 30-42, 1996.

[52] B. C. Warf, J. Fok-Seang, R. H. Miller, "Evidence for the ventral origin of oligodendrocyte precursors in the rat spinal cord. Journal of Neuroscience, Vol. 11, pp. 2477-2488, 1991.

[53] Vallstedt, J. M. Klos, J. Ericson, “Multiple dorsoventral origins of oligodendrocyte generation in the spinal cord and hindbrain" Neuron, vol. 45, pp. 55-67, 2005.

[54] W. D. Richardson, N. Kessaris, N. Pringle, “Oligodendrocyte wars. Nature Reviews Neuroscience, vol. 7, pp. 11-8, 2006.

[55] N. Tekki-Kessaris, R. Woodruff, A. C. Hall, W. Gaffield, S. Kimura, C. D. Stiles, D. H. Rowitch, W. D. Richardson, "Hedgehog-dependent oligodendrocyte lineage specification in the telencephalon," Development, vol. 128, pp. 2545-2554, 2001.

[56] N. Kessaris, M. Fogarty, P. Iannarelli, M. Grist, M. Wegner, W. D. Richardson, "Competing waves of oligodendrocytes in the forebrain and postnatal elimination of an embryonic lineage," Nature Neuroscience, vol. 9, pp. 173-179, 2006.

[57] Nishiyama, X. H. Lin, N. Giese, C.H. Heldin, W.B. Stallcup, “Co-localization of NG2 proteoglycan and PDGF alpha-receptor on O2A progenitor cells in the developing rat brain," Journal of Neuroscience Research, vol. 43, pp. 299-314, 1996.

[58] M. Diers-Fenger, F. Kirchhoff, H. Kettenmann, J. M. Levine, J. Trotter, "AN2/NG2 protein-expressing glial progenitor cells in the murine CNS: isolation, differentiation, and association with radial glia," Glia, vol. 34, pp. 213-228, 2001.

[59] M. Berry, P. Hubbard, A. M. Butt, "Cytology and lineage of NG2-positive glia," Journal of Neurocytology, vol. 31, pp. 457-467, 2002.

[60] J. M. Levine, F. Stincone, Y. S. Lee, “Development and differentiation of glial precursor cells in the rat cerebellum," Glia, vol. 7, pp. 307-321, 1993.

[61] H. Grandel, M. Brand, "Comparative aspects of adult neural stem cell activity in vertebrates," Development Genes and Evolution, in press, 2012.

[62] Y. Kozorovitskiy, E. Gould, "Adult neurogenesis: a mechanism for brain repair?," Journal of Clinical Experimental Neuropsychology, vol. 25, pp. 721-732, 2003.

[63] G. Martino, S. Pluchino, L. Bonfanti, M. Schwartz, “Brain regeneration in physiology and pathology: The immune signature driving therapeutic plasticity of neural stem cells," Physiological Reviews, vol. 91, pp. 1281-1304, 2011.

[64] P. Ferretti, "Is there a relationship between adult neurogenesis and neuron generation following injury across evolution?" European Journal of Neuroscience, vol. 34, pp. 951-962, 2011. 
[65] G. K. Zupanc, "Neurogenesis and neuronal regeneration in the adult fish brain," Journal of Comparative Physiology A, vol. 192, pp. 649-670, 2006.

[66] B. W. Lindsey, V. Tropepe, "A comparative framework for understanding the biological principles of adult neurogenesis," Progress in Neurobiology, vol. 80, pp. 281-307, 2006.

[67] U. S., Sohur, J. G. Emsley, B. D., Mitchell, J. D. Macklis, “Adult neurogenesis and cellular brain repair with neural progenitors, precursors and stem cells," Philosophical Transactions of the Royal Society B-Biological Sciences, vol. 361, pp. 1477-1497, 2006.

[68] G. Ponti, P. Crociara, M. Armentano, L. Bonfanti, “Adult neurogenesis without germinal layers: the "atypical" cerebellum of rabbits," Archives Italiennes de Biologie, vol. 148, pp. 147-158, 2010.

[69] O. Koizumi, H. R. Bode, "Plasticity in the nervous system of adult hydra. III. Conversion of neurons to expression of a vasopressin-like immunoreactivity depends on axial location," Journal of Neuroscience, vol. 11, pp. 2011-2020, 1991.

[70] Y. Umesono, K. Agata, "Evolution and regeneration of the planarian central nervous system," Development Growth and Differentiation, vol. 51, pp. 185-195, 2009.

[71] R. F. Sirbulescu, G. K. Zupanc, "Spinal cord repair in regeneration-competent vertebrates: Adult teleost fish as a model system," Brain Research Review, vol. 67, pp. 73-93, 2011.

[72] T. Endo, J. Yoshino, K. Kado, S. Tochinai, "Brain regeneration in anuran amphibians," Development Growth and Differentiation, vol. 49, pp. 121-129, 2007.

[73] P. M. Lledo, M. Alonso, M.S. Grubb, "Adult neurogenesis and functional plasticity in neuronal circuits," Nature Reviews Neuroscience, vol. 7, pp. 179-193, 2006.

[74] G. Kempermann, "New neurons for 'survival of the fittest'," Nature Reviews Neuroscience, vol. 13, pp. 727-736, 2012.

[75] K. Whalley, S. Gogel, S. Lange, P. Ferretti, "Changes in progenitor populations and ongoing neurogenesis in the regenerating chick spinal cord," Developmental Biology, vol. 332, pp. 234-245, 2009.

[76] Jopling, C., Sleep, E., Raya, M., Marti, M., Raya, A., and Belmonte, J.C. (2010) Zebrafish heart regeneration occurs by cardiomyocyte dedifferentiation and proliferation. Nature 464, 606-609.

[77] L. Mescher, A. W. Neff, "Limb regeneration in amphibians: immunological considerations," ScientificWorldJournal, vol. 6, pp. 1-11, 2006.

[78] Z. M. Weil, G. J. Norman, A. C. DeVries, R. J. Nelson, “The injured nervous system: a Darwinian perspective," Progress in Neurobiology, vol. 86, pp. 48-59, 2008. 
[79] K. M. Johnson, R. Boonstra, J. M. Wojtowicz, "Hippocampal neurogenesis in foodstoring red squirrels: the impact of age and spatial behaviour," Genes Brain and Behaviour, vol. 9, pp. 583-591, 2010.

[80] J. M. Barker, R. Boonstra, J. M. Wojtowicz, "From pattern to pourpose: how comparative studies contribute to understanding the function of adult neurogenesis," European Journal of Neuroscience, vol. 34, pp. 963-977, 2011.

[81] N. Sanai, T. Nguyen, R. A. Ihrie, Z. Mirzadeh, H.H. Tsai, M. Wong, N. Gupta, M.S. Berger, E. Huang, J. M. Garcia-Verdugo, D.H. Rowitch, A. Alvarez-Buylla, "Corridors of migrating neurons in the human brain and their decline during infancy," Nature, vol. 478, pp. 382-386, 2011.

[82] M. V. Kokoeva, H. Yin, J. S. Flier, "Neurogenesis in the hypothalamus of adult mice: potential role in energy balance," Science, vol. 310, pp. 679-683, 2005.

[83] G. H. Kuhn, K. Blomgren, “Developmental dysregulation of adult neurogenesis,” European Journal of Neuroscience, vol. 33, pp. 1115-1122, 2011.

[84] M. Feliciano, A. Bordey, "Newborn cortical neurons: only for neonates?" Trends in Neurosciences, in press, 2012.

[85] J. G. Emsley, B. D. Mitchell, G. Kempermann, J. D. Macklis, "Adult neurogenesis and repair of the adult CNS with neural progenitors, precursors, and stem cells," Progress in Neurobiology, vol. 75, pp. 321-341, 2005.

[86] K. Ohira, T. Furuta, H. Hioki, K. C. Nakamura, E. Kuramoto, Y. Tanaka, N. Funatsu, K. Shimizu, T. Oishi, M. Hayashi, T. Miyakawa, T. Kaneko, S. Nakamura, "Ischemiainduced neurogenesis of neocortical layer 1 progenitor cells," Nature Neuroscience, vol. 13, pp. 173-179, 2009.

[87] A. Pierce, A. W. Xu, “De novo neurogenesis in adult hypothalamus as a compensatory mechanism to regulate energy balance," Journal of Neuroscience, vol. 30, pp. 723-730, 2010.

[88] P. J. Bernier, A. Bédard, J. Vinet, M. Lévesque, A. Parent, "Newly generated neurons in the amygdala and adjoing cortex of adult primates," Proceedings of the National Academy of Science U.S.A., vol. 99, pp. 11464-11469, 2002.

[89] Gould, N. Vail, M. Wagers, C.G. Gross, "Adult-generated hippocampal and neocortical neurons in macaques have a transient existence," Proceedings of the National Academy of Science U.S.A., vol. 98, pp. 10910-10917, 2001.

[90] J. S. Snyder, J. S. Choe, M. A. Clifford, S. I. Jeurling, P. Hurley, A. Brown, J. F. Kamhi, H. A. Cameron, "Adult-born hippocampal neurons are more numerous, faster-maturing and more involved in behavior in rats than in mice," Journal of Neuroscience, vol. 29, pp. 14484-14495, 2010. 
[91] Kempermann, E. J. Chesler, L. Lu, R. W. Williams, F. H. Gage, “Natural variation and genetic covariance in adult hippocampal neurogenesis," Proceedings of the National Academy of Science U.S.A., vol. 103, pp. 780-785, 2006.

[92] P. J. Clark, R. A. Kohman, D. S. Miller, T. K. Bhattacharya, W. J. Brzezinska, J. S. Rhodes, "Genetic influences on exercise-induced adult hippocampal neurogenesis across 12 divergent mouse strains," Genes Brain and Behaviour, vol. 10, pp. 345-353, 2011.

[93] Amrein, K. Isler, H. P. Lipp, "Comparing adult hippocampal neurogenesis in mammalian species and orders: influence of chronological age and life history stage," European Journal of Neuroscience, vol. 34, pp. 978-987, 2011.

[94] M. Zhao, S. Momma, K. Delfani, M. Carlen, R. M. Cassidy, C. B. Johansson, H. Brismar, O. Shupliakov, J. Frisen, A. M. Janson, "Evidence for neurogenesis in the adult mammalian substantia nigra," Proceedings of the National Academy of Science U.S.A., vol. 100, pp. 7925-7930, 2003.

[95] L. E. Rivers, K. M. Young, M. Rizzi, F. Jamen, K. Psachoulia, A. Wade, N. Kessaris, W. D. Richardson, "PDGFRA/NG2 glia generate myelinating oligodendrocytes and piriform projection neurons in adult mice," Nature Neuroscience, vol. 11, pp. 1392-1401, 2008.

[96] Guo, Y. Maeda, J. Ma, J. Xu, M. Horiuchi, L. Miers, F. Vaccarino, D. Pleasure, "Pyramidal neurons are generated from oligodendroglial progenitor cells in adult piriform cortex," Journal of Neuroscience, vol. 30, pp. 12036-12049, 2010.

[97] S. H. Kang, M. Fukaya, J. K. Yang, J. D. Rothstein, D. E. Bergles, “NG2+ CNS glial progenitors remain committed to the oligodendrocyte lineage in postnatal life and following neurodegeneration," Neuron, vol. 68, pp. 668-681, 2010.

[98] W. D. Richardson, K. M. Young, R. B. Tripathi, I. McKenzie, "NG2-glia as multipotent neural stem cells: fact or fantasy?" Neuron, vol. 70, pp. 661-673, 2011.

[99] Frielingsdorf, K. Schwarz, P. Brundin, P. Mohapel, "No evidence for new dopaminergic neurons in the adult mammalian substantia nigra," Proceedings of the National Academy of Science U.S.A., vol. 101, pp. 10177-10182, 2004.

[100] M. Migaud, M. Batailler, S. Segura, A. Duittoz, I. Franceschini, D. Pillon, “Emerging new sites for adult neurogenesis in the mammalian brain: a comparative study between the hypothalamus and the classical neurogenic zones," European Journal of Neuroscience, vol. 32, pp. 2042-2052, 2010.

[101] Y. Xu, N. Tamamaki, T. Noda, K. Kimura, Y. Itokazu, N. Matsumoto, M. Dezawa, C. Ide, "Neurogenesis in the ependymal layer of the adult rat 3rd ventricle," Experimental Neurology, vol. 192, pp. 251-264, 2005.

[102] M. V. Kokoeva, H. Yin, J. S. Flier, “Evidence for constitutive neural cell proliferation in the adult murine hypothalamus," Journal of Comparative Neurology, vol. 505, pp. 209-220, 2007. 
[103] L. Bennett, M. Yang, G. Enikolopov, L. Iacovitti, “Circumventricular organs: a novel site of neural stem cells in the adult brain," Molecular and Cellular Neuroscience, vol. 41, pp. 337-347, 2009.

[104] M. Pérez-Martín, M. Cifuentes, J. M. Grondona, M. D. López-Avalos, U. Gómez-Pinedo, J. M. García-Verdugo, P. Fernández-Llebrez, "IGF-I stimulates neurogenesis in the hypothalamus of adult rats," European Journal of Neuroscience, vol. 31, pp. 1533-1548, 2010.

[105] K. Matsuzaki, M. Katakura, T. Hara, G. Li, M. Hashimoto, O. Shido, "Proliferation of neuronal progenitor cells and neuronal differentiation in the hypothalamus are enhanced in heat-acclimated rats," Pflugers Archiv-European Journal of Physiology, vol. 458, pp. 661-673, 2009.

[106] Pekcec, W. Löscher, H. Potschka, "Neurogenesis in the adult rat piriform cortex. Neuroreport, vol. 17, pp. 571-574, 2006.

[107] L. A. Shapiro, K. L. Ng, Q. Y. Zhou, C. E. Ribak, “Olfactory enrichment enhances the survival of newly born cortical neurons in adult mice," Neuroreport, vol. 18, pp. 981-985, 2007.

[108] M. A. Gomez-Climent, E. Castillo-Gomez, E. Varea, R. Guirado, J. M. Blasco-Ibanez, C. Crespo, F. J. Martinez-Guijarro, J. Nacher, “A population of prenatally generated cells in the rat paleocortex maintains an immature neuronal phenotype into adulthood," Cerebral Cortex, vol. 18, pp. 2229-2240, 2008.

[109] T. Seki, Y. Arai, "Expression of highly polysialylated NCAM in the neocortex and piriform cortex of the developing and the adult rat," Anatomy and Embryology (Berl.), vol. 184, pp. 395-401, 1991.

[110] L. Bonfanti, "PSA-NCAM in mammalian structural plasticity and neurogenesis," Progress in Neurobiology, vol. 80, pp. 129-164, 2006.

[111] L. Bonfanti, J. Nacher, "New scenarios for neuronal structural plasticity in non-neurogenic brain parenchyma: the case of cortical layer II immature neurons," Progress in Neurobiology, vol. 98, pp. 1-15, 2012.

[112] M. Vessal, C. Darian-Smith, "Adult neurogenesis occurs in primate sensorimotor cortex following cervical dorsal rhizotomy," Journal of Neuroscience, vol. 30, pp. 8613-8623, 2010.

[113] Bi, B, Salmaso N, Komitova M, Simonini MV, Silbereis J, Cheng E, Kim J, Luft S, Ment LR, Horvath TL, Schwartz ML, Vaccarino FM, Cortical glial fibrillary acidic protein-positive cells generate neurons after perinatal hypoxic injury. Journal of Neuroscience 31, 9205-9221, 2011.

[114] Tattersfield A, Croon R, Liu Y, Kells A, Faull R, Connor B. Neurogenesis in the striatum of the quinolinic acid lesion model of Huntington's disease. Neuroscience 127, 319-332, 2004. 
[115] Parent J, Vexler Z, Gong C, Derugin N, Ferriero D. Rat forebrain neurogenesis and striatal neuron replacement after focal stroke. Annals of Neurology, 52, 802-813, 2002.

[116] Liu F, You Y, Li X, Ma T, Nie Y, Wei B, Li T, Lin H, Yang Z, Brain injury does not alter the intrinsic differentiation potential of adult neuroblasts. Journal of Neuroscience, 29, 5075-5087.

[117] Hoehn B, Palmer T, Steinberg G. Neurogenesis in rats after focal cerebral ischemia is enhanced by indomethacin. Stroke 36, 2718-2724, 2005.

[118] Nakagomi T, Molnár Z, Nakano-Doi A, Taguchi A, Saino O, Kubo S, et al. Ischemiainduced neural stem/progenitor cells in the pia mater following cortical infarction. Stem cells and development 20, 2037-2051, 2011.

[119] Decimo I, Bifari F, Rodriguez F, Malpeli G, Dolci S, Lavarini V, et al. Nestin- and doublecortin-positive cells reside in adult spinal cord meninges and participate in injury-induced parenchymal reaction. Stem cells 29, 2062-2076, 2011.

[120] Shimada IS, Peterson BM, Spees JL Isolation of locally derived stem/progenitor cells from the peri-infarct area that do not migrate from the lateral ventricle after cortical stroke. Stroke 41, 3552-3560, 2010.

[121] Shimada I, LeComte M, Granger J, Quinlan N, Spees J. Self-renewal and differentiation of reactive astrocyte-derived neural stem/progenitor cells isolated from the cortical peri-infarct area after stroke. The Journal of neuroscience: the official journal of the Society for Neuroscience 32, 7926-7940, 2012.

[122] T. Mantamadiotis, T. Lemberger, S. C. Bleckmann, H. Kern, O. Kretz, A. Martin Villalba, F. Tronche, C. Kellendonk, D. Gau, J. Kapfhammer, C. Otto, W. Schmid, G. Schütz, "Disruption of CREB function in brain leads to neurodegeneration," Nature Genetics, vol. 31, pp. 47-54, 2002.

[123] Suh H, Consiglio A, Ray J, Sawai T, D'Amour KA, Gage FH, In vivo fate analysis reveals the multipotent and self-renewal capacities of Sox2+ neural stem cells in the adult hippocampus. Cell Stem Cell, 1, 515-528, 2007.

[124] Cheng LC, Pastrana E, Tavazoie M, Doetsch F miR-124 regulates adult neurogenesis in the subventricular zone stem cell niche. Nature Neuroscience 12, 399-408, 2009.

[125] Steiner B, Klempin F, Wang L, Kott M, Kettenmann H, Kempermann G, Type-2 cells as link between glial and neuronal lineage in adult hippocampal neurogenesis. Glia 54, 805-814, 2006.

[126] Doetsch F, Petreanu L, Caille I, Garcia-Verdugo JM, Alvarez-Buylla A EGF converts transit-amplifying neurogenic precursors in the adult brain into multipotent stem cells. Neuron 36, 1021-1034, 2002.

[127] Burns T, Verfaillie C, Low W. Stem cells for ischemic brain injury: a critical review. Journal of Comparative Neurology 515, 125-144, 2009. 
[128] E. Boda, A. Buffo, "Glial cells in non-germinal territories: insights into their stem/ progenitor properties in the intact and injured nervous tissue," Archives Italiennes de Biologie, vol. 148, pp. 119-136, 2010.

[129] W. B. Stallcup, L. Beasley, "Bipotential glial precursor cells of the optic nerve express the NG2 proteoglycan," Journal of Neuroscience, vol. 7, pp. 2737-2744, 1987.

[130] R. Reynolds, M. Dawson, D. Papadopoulos, A. Polito, I. C. Di Bello, D. Pham-Dinh, J. Levine, "The response of NG2-expressing oligodendrocyte progenitors to demyelination in MOG-EAE and MS," Journal of Neurocytology, vol. 31, pp. 523-536, 2002.

[131] A. Aguirre, R. Chittajallu, S. Belachew, V. Gallo, “NG2-expressing cells in the subventricular zone are type C-like cells and contribute to interneuron generation in the postnatal hippocampus," Journal of Cell Biology, vol. 165, pp. 575-589, 2004.

[132] K. L. Ligon, S. P. Fancy, R. J. Franklin, D. H. Rowitch, “Olig gene function in CNS development and disease," Glia, vol. 54, pp. 1-10, 2006.

[133] R. Reynolds, R. Hardy, “Oligodendroglial progenitors labeled with the O4 antibody persist in the adult rat cerebral cortex in vivo," Journal of Neuroscience Research, vol. 47, pp. 455-470, 1997.

[134] Q. Zhou, S. Wang, D. J. Anderson, "Identification of a novel family of oligodendrocyte lineage-specific basic helix-loop-helix transcription factors," Neuron, vol. 25, pp. 331-343, 2000.

[135] Bu, A. Banki, Q. Wu, A. Nishiyama, "Increased NG2(+) glial cell proliferation and oligodendrocyte generation in the hypomyelinating mutant shiverer," Glia, vol. 48, pp. 51-63, 2004.

[136] R. J. Franklin, S. C. Barnett, "Do olfactory glia have advantages over Schwann cells for CNS repair?" Journal of Neuroscience Research, vol. 50, pp. 665-672, 1997.

[137] L. Dimou, C. Simon, F. Kirchhoff, H. Takebayashi, M. Gotz, "Progeny of Olig2-expressing progenitors in the gray and white matter of the adult mouse cerebral cortex," Journal of Neuroscience, vol. 28, pp. 10434-10442, 2008.

[138] M. Komitova, E. Perfilieva, B. Mattsson, P.S. Eriksson, B. B. Johansson, “Enriched environment after focal cortical ischemia enhances the generation of astroglia and NG2 positive polydendrocytes in adult rat neocortex," Experimental Neurology, vol. 199, pp. 113-121, 2006.

[139] M. C. Raff, R. H. Miller, M. Noble, “A glial progenitor cell that develops in vitro into an astrocyte or an oligodendrocyte depending on culture medium," Nature, vol. 303, pp. 390-396, 1983.

[140] Espinosa de los Monteros, R. Bernard, B. Tiller, P. Rouget, J. de Vellis, "Grafting of fast blue labeled glial cells into neonatal rat brain: differential survival and migration 
among cell types," International Journal of Developmental Neuroscience, vol. 11, pp. 625-639, 1993.

[141] K. Groves, S. C. Barnett, R. J. Franklin, A. J. Crang, M. Mayer, W. F. Blakemore, M. Noble, "Repair of demyelinated lesions by transplantation of purified O-2A progenitor cells. Nature, vol. 362, pp. 453-455, 1993.

[142] M. Riederer, "Microtubule-associated protein 1B, a growth and phosphorilated scaffold protein," Brain Research Bulletin, vol. 71, pp. 541-558, 2007.

[143] Encinas JM, Michurina TV, Peunova N, Park JH, Tordo J, Peterson DA, Fishell G, Koulakov A, Enikolopov G, Division-coupled astrocytic differentiation and age-related depletion of neural stem cells in the adult hippocampus, Cell Stem Cell, vol. 8, pp. 566-579, 2011.

[144] G. Ponti, K. Obernier, C. Guinto, L. Jose, L. Bonfanti, A. Alvarez-Buylla, The cell cycle and lineage progression of neural progenitors in the ventricular-subventricular zones of adult mice. Proceedings of the National Academy of Science U.S.A., in press, 2013.

[145] Simon, M. Götz, L. Dimou, "Progenitors in the adult cerebral cortex: cell cycle properties and regulation by physiological stimuli and injury," Glia, vol. 59, pp. 869-881, 2011.

[146] S. Sugiarto, A. I. Persson, E. G. Munoz et al., "Asymmetricdefective oligodendrocyte progenitors are glioma precursors," Cancer Cell, vol. 20, pp. 320-340, 2011. 